\title{
Adrenal neuroblastoma in adults: A case report and review of the literature
}

\section{Azzi. Nadjet, Yakoubi. Becherki *,}

Department of University Hospital of Bab el Oued Algiers- Algeria.

*Corresponding author: Yakoubi. Becherki, Department of University Hospital of Bab el Oued Algiers- Algeria.E-mail: becherky@yahoo.fr Received Date: February 2, 2020; Accepted Date: February 13, 2020; Published Date: February $18,2020$.

Citation: Nadjet A, Becherki Y. (2020) Management of Hydatid Cyst of the Spleen. A Case Report. Journal of Clinical Case Reports and Studies, 1(1): 10.31579/CCRS/2020/002

Copyright: (c) 2020. Yakoubi. Becherki. This is an open-access article distributed under the terms of the Creative Commons Attribution License, which permits unrestricted use, distribution, and reproduction in any medium, provided the original author and source are credited.

\section{Abstract}

the clinical manifestations of Neuroblastoma are very variable. They depend on the site of the primary tumor, most often in the abdomen, along the spine or in the adrenal gland Very often, it is the existence of metastases which reveals the disease, with bone pain, and / or difficulty in walking or urinary problems. Management must be carried out in a specialized multidisciplinary team. This will confirm, by imaging, the existence of a neuroblastoma, perform a biological assessment, search for metastases from a distance, and define prognostic factors and the appropriate therapeutic strategy.

Key Words: adrenal tumor; neuroblastoma adult

\section{Introduction}

Neuroblastoma is the most common extra-cranial solid malignant tumor in young children. It is a malignant tumor derived from cells originating in the tissues that give rise to the sympathetic nervous system. It can be found in front of the spine and in the internal part of the adrenal gland.

It most often sits behind the peritoneum.

Neuroblastoma accounts for about $10 \%$ of solid tumors in children. It is the most common malignant neoplasm of infants: $50 \%$ of affected children are less than 2 years old. In a third of cases, the tumor occurs in a child under one year of age and in $95 \%$ of cases before the age of 10 . For the majority of neuroblastomas, there is no known cause and they remain exceptional in adults.

Predisposition syndromes have been described: Neurofibromatosis type 1, Hirschsprung disease, Ondine syndrome. Very exceptionally, neuroblastoma has been observed in association with BeckwithWiedemann syndrome or Di-George syndrome.

\section{Observation}

Patient C.N female; 22 year old who has no particular pathological history; who consults for chronic constipation associated with dysmenorrhea; the patient shows no signs of hypercorticism; no signs of hyper androgenism or hypokalemia.

Also the absence of Menard's triad. Biological examinations:

$$
\text { Urinary metanephrines }=0.12 \mathrm{mg} / 24 \mathrm{~h}(0-1) \text {. }
$$

Cortisol $=284.4 \mathrm{nmol} / 1$. Cortisol after minute braking $=$ $22.3 \mathrm{nmol} / 1(+)$.

Testosterone less than $0.45 \mathrm{nmol} / 1$. - SDHEA $=116.7 \mathrm{ug} / \mathrm{dl}$.

Imaging abdominal pelvic MRI: fig. 1 Fig. 1. Right retroperitoneal supra-renal mass of 124/75/86 mm enhancing heterogeneously and delimiting necrosis areas of malignant appearance compressing the inferior vena cava.

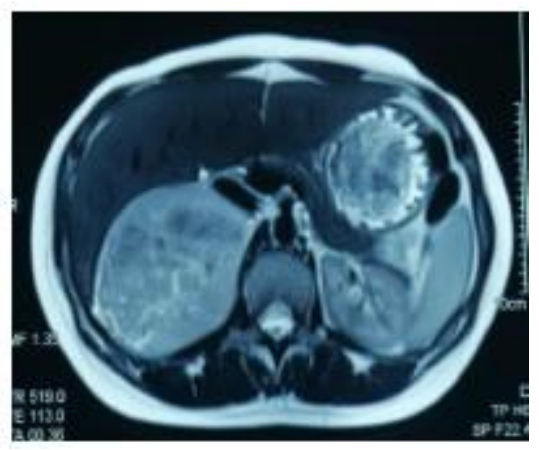

Fig. 1 MRI Axial Section

Abdominal Doppler ultrasound: Lower vena cava compressed by a right adrenal mass without thrombosis and without downstream impact.

Abdominal CT: Fig. 2 (a; b): Probable right adrenal mass looking suspicious. 

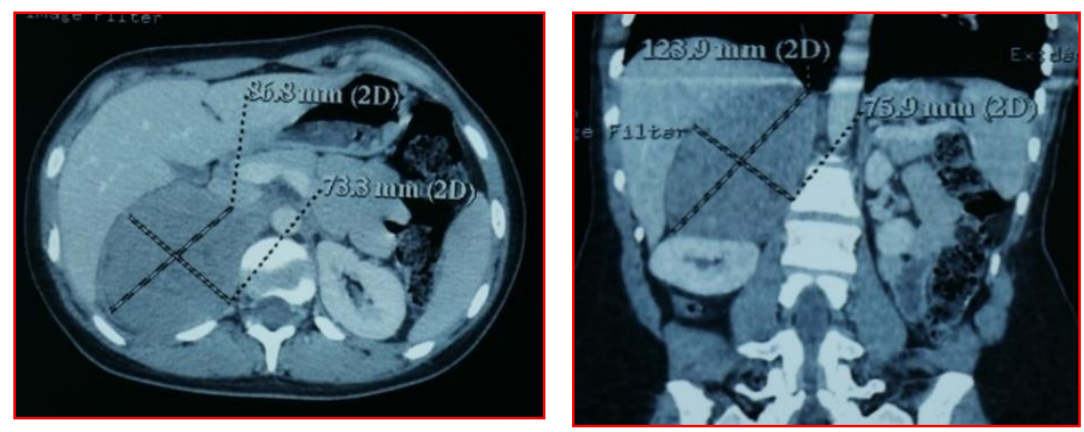

Abdominal CT: Fig2 (a; b) axial and coronal sections Probable right adrenal mass looking suspicious.

\section{Surgery}

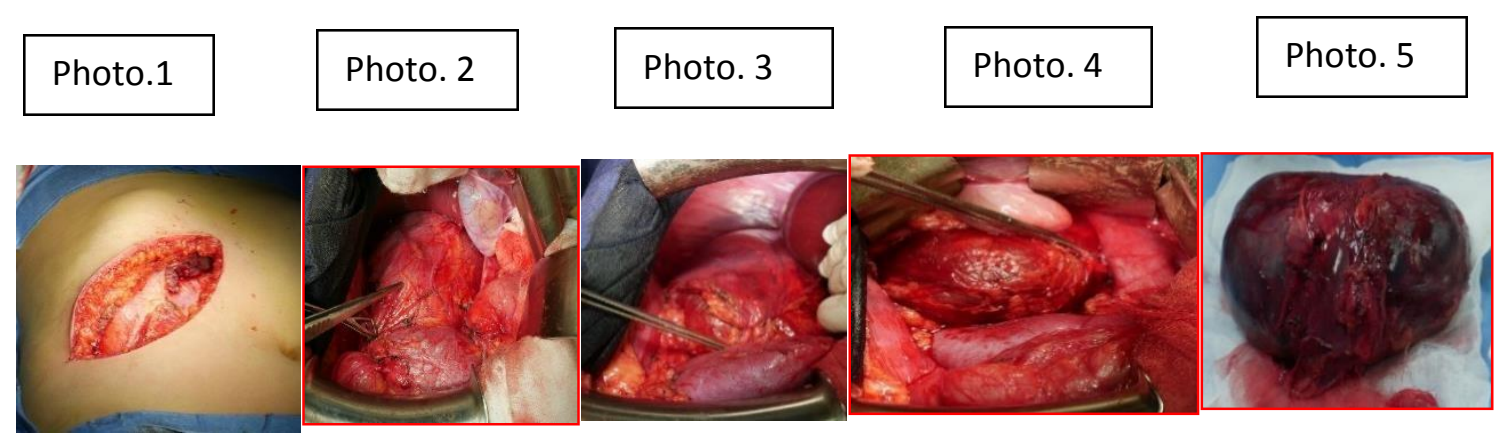

- Photo 1 Right costal incision.

- Photo 2 Adrenal tumor driving the kidney down; the VCI on the right.

- Photo3 Dissection of the mass compared to the IVC after dislocation of the liver.

- Photo 4: release of the tumor from its vascular attachments.

- Photo5 Neuroblastoma undergoing differentiation: (anatomo pathology study).

\section{Post-operative follow-up:}

The extension assessment including a bone scan and a chest CT shows a suspicious thymic retro-sternal mass. The patient was operated 03 months after the first intervention or a thymic resection was carried out and the anatomo-pathological study returns in favor of a benign thymic lesion.

\section{Discussion}

Neuroblastoma is a tumor originating from ganglion cells derived from the neural crest. It is the most common solid extra-cerebral tumor in children, responsible for $15 \%$ of deaths from neoplasia. $36 \%$ of cases are diagnosed before the age of one, $75 \%$ before five, and more than $97 \%$ before the age of ten. The tumor biopsy is used to look for abnormalities in the tumor chromosomes, which are used to classify the level of aggressiveness of the tumor: abnormalities in number of best prognosis.

The evolution depends on the age of the child at the time of diagnosis, the tumor extension. The therapeutic strategy is built taking into account these three factors: for tumors that can be immediately treated, surgery alone will most often be sufficient; for tumors that are not immediately operable, pre-surgical chemotherapy is necessary before surgery. The evolution is very variable. Indeed, in infants, certain localized or metastatic tumors can regress spontaneously; some others, in older children, escape treatment despite the use of very aggressive combinations.

In metastatic forms and / or in case of amplification of MYCN, consolidation by high-dose chemotherapy with hematopoietic stem cell transplantation is necessary, as well as radiotherapy of the tumor and maintenance treatment comprising immunotherapy. Survival varies according to the identified risk, between more than $90 \%$ of recovery for localized forms and young children, to 40 to $50 \%$ in the most serious forms.

The search for a genetic anomaly, initial or at relapse, makes it possible to develop treatments targeting these anomalies in the event of noncontrol of the disease by conventional treatments.

One of the reasons for its rarity in adulthood and adolescence could be attributed to the tendency of these tumors to spontaneous regression or down staging without any treatment. 
In adults, the anatomical localizations are most often abdominal in $60 \%$, (of which 32 - 35\% adrenal), followed by the medial localizations $20 \%$ and pelvic. To date, no environmental factors or parental exposure have been found to explain the occurrence of the disease.
Risk groups are defined according to the anatomical stage, age at diagnosis, histopathology classification and the amplified or nonamplified status of the N-MYC oncogene, the whole defining the criteria of the International Neuroblastoma Staging System (INSS) Table1.

\title{
Table 1. Neuroblastoma Clinical Stages
}

\section{International Neuroblastoma Staging System (INSS):}

\author{
stage H. bocalized kumor contined to the area of origin. \\ stage 2A: Unilateral tumor with incomplete gross resection; identifiabie ipsiateral and \\ contsalateral ymon node negative for tumor.

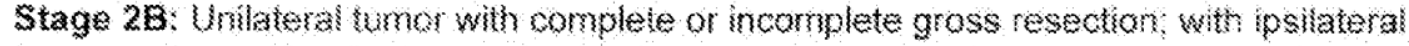 \\ ymph node positive for tumor; identifable contralateral lymph node negative for lumor. \\ \$tage 3. Tumor infitrating across midline with or without regional lymph node \\ involvement; or unilateral sumor with contralateral lymph node involvement or shiding \\ kimor with biateral iymph node involvernent. \\ Stage 4: Dissemination of tumor to distant lymph nodes, bone marrow, bone, fiver, or \\ other organs except as dented by Stage 45 . \\ \$tage 45: Age < year old whth localized primary tumor as defined in stage of 2 , with \\ dissermination kmited to liver, skin, or bone marrow (less than 10 percent of nuskeated \\ bone marrow ceise are tumors).
}

\section{International Neuroblastoma Risk Group Staqing System (NRGSS):}

\author{
Stage 1: Localized disease without image defined risk factors. \\ Stage L2: Localized disease with image defined risk factors. \\ Stage M: Metastatic disease. \\ Stage MS: Metastatio disease "special" where MS is equivatent to stage 49.
}

Surgical resection is the standard curative treatment. Chemotherapy is indicated in locally advanced or metastatic forms. The most used molecules: Cyclophosphamide, Cisplatin, and Doxorubicin...Radiotherapy is an important complement to chemotherapy.

Adult forms, however, are exceptional. The few publications on this subject seem to show significant differences from pediatric forms, in particular the very indolent nature of adult forms and their most often fatal prognosis.

\section{Conclusion}

It should be noted that Adrenal Neuroblastomas are very rare in adulthood, but it should be borne in mind that each adrenal tumor without specific characteristics has a high probability of being identified as Neuroblastoma.

\section{References}

1. McLean TW, Iskandar SS, Shimada H et al. (2004).
Neuroblastoma in an adult. Urology, 64: 1232.

2. Adrenal Neuroblastoma in an Adult: Report of a Case; Fatih Ata Genc1, Murat Aksoy1, Yersu Kapran2, Fatih Tunca1, Refik Tanakol3, Yilmaz Basar1, and Tarik Terzioglu 1

3. JPddiatrPulriculture1998; 11: 259-64: Dépistage du neuroblastome.

4. Le Neuroblastome Qu'attend le clinicien de l'imagerie? S. Sedrati, N. Allali, M. Chelloui, L. Chat, R. Dafiri Service de Radiologie, Hôpital d'Enfants - Maternité CHU de Rabat - Maroc.

5. Neuroblastoma in adults and adolescents: an indolent course with poor survival; Loraine M.Franks M.D; Andrew Bollen M.D, Robert C. Seeger M.D.

6. N. Aloui-Kasbi, S. Felah, I. Bellagha, S. Barsaoui b, A. (2003). Hammou a aService de radiologie, hôpital d'enfants de Tunis, 1007 Jebbari, Bâb Saadoun, Tunis, Tunisie bService de pédiatrie générale, 2e étage, hôpital d'enfants de Tunis, 1007 Jebbari, Bâb Saadoun, Tunis, Tunisie Journal de pédiatrie et de puériculture Volume 17,$1 ; 28-33$ 